\title{
Tailoring the Molecular and Thermo-Mechanical Properties of Kraft Lignin by Ultrafiltration
}

Article in Journal of Applied Polymer Science - September 2014

Impact Factor: $1.77 \cdot$ DOI: 10.1002/app.40799

CITATIONS

12

10 authors, including:

\section{Olena Sevastyanova}

KTH Royal Institute of Technology

37 PUBLICATIONS 208 CITATIONS

SEE PROFILE

\section{Liming Zhang}

KTH Royal Institute of Technology

28 PUBLICATIONS 642 CITATIONS

SEE PROFILE

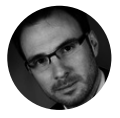

Heiko Lange

University of Rome Tor Vergata

34 PUBLICATIONS 623 CITATIONS

SEE PROFILE

Claudia Crestini

University of Rome Tor Vergata

151 PUBLICATIONS 3,207 CITATIONS

SEE PROFILE 


\title{
Applied Polymer
}

\section{Tailoring the Molecular and Thermo-Mechanical Properties of Kraft Lignin by Ultrafiltration}

\author{
Olena Sevastyanova, ${ }^{1}$ Mikaela Helander, ${ }^{2}$ Sudip Chowdhury, ${ }^{3}$ Heiko Lange, ${ }^{4}$ Helena Wedin, ${ }^{1}$ \\ Liming Zhang, ${ }^{1}$ Monica Ek, ${ }^{1}$ John F. Kadla, ${ }^{3}$ Claudia Crestini, ${ }^{4}$ Mikael E. Lindström ${ }^{1}$ \\ ${ }^{1}$ Department of Fibre and Polymer Technology, KTH Royal Institute of Technology, Stockholm SE-100 44, Sweden \\ 2WWSC Wallenberg Wood Science Center, KTH Royal Institute of Technology, Stockholm and Chalmers University of Technology, \\ Gothenburg, Sweden \\ ${ }^{3}$ Faculty of Forestry, Biomaterials Chemistry, UBC University of British Columbia, Vancouver V6T 1Z4, British Columbia, Canada \\ ${ }^{4}$ Department of Chemical Sciences and Technologies, University of Rome 'Tor Vergata', Rome 00133, Italy \\ Correspondence to: O. Sevastyanova (E-mail: olena@kth.se)
}

\begin{abstract}
This study has shown that ultrafiltration allows the selective extraction from industrial black liquors of lignin fraction with specific thermo-mechanical properties, which can be matched to the intended end uses. Ultrafiltration resulted in the efficient fractionation of kraft lignin according to its molecular weight, with an accumulation of sulfur-containing compounds in the lowmolecular weight fractions. The obtained lignin samples had a varying quantities of functional groups, which correlated with their molecular weight with decreased molecular size, the lignin fractions had a higher amount of phenolic hydroxyl groups and fewer aliphatic hydroxyl groups. Depending on the molecular weight, glass-transition temperatures $\left(T_{g}\right)$ between 70 and $170^{\circ} \mathrm{C}$ were obtained for lignin samples isolated from the same batch of black liquor, a tendency confirmed by two independent methods, DSC, and dynamic rheology (DMA). The Fox-Flory equation adequately described the relationship between the number average molecular masses $\left(M_{n}\right)$ and $T_{g}$ 's-irrespective of the method applied. DMA showed that low-molecular-weight lignin exhibits a good flow behavior as well as high-temperature crosslinking capability. Unfractionated and high molecular weight lignin $\left(M_{w}>5 \mathrm{kDa}\right)$, on the other hand, do not soften sufficiently and may require additional modifications for use in thermal processings where melt-flow is required as the first step. (C) 2014 Wiley Periodicals, Inc. J. Appl. Polym. Sci. 2014, 131, 40799.
\end{abstract}

KEYWORDS: biopolymers and renewable polymers; crosslinking; glass transition; rheology; thermal properties

Received 24 September 2013; accepted 28 March 2014

DOI: 10.1002/app.40799

\section{INTRODUCTION}

Biorefinery of forest-based products represents an emerging opportunity that may have a dramatic impact on future energy and material supplies, as well as on the forest industry itself. ${ }^{1}$ The primary aim of modern integrated forest biorefineries is to produce high-value products, such as chemicals and biopolymers, while improving the efficiency and profitability of their core operations. The three major components of lignocellulosic materials are cellulose, hemicellulose, and lignin. Traditional pulp and paper processes, as well as most of the current biorefinery projects, concentrate on the utilization of cellulose and hemicellulose. Lignin, the second most abundant macromolecule in nature, is usually considered to be a low-value residue and is simply burnt for the production of process steam and energy; for an all-encompassing biorefinery concept; however, the value-adding utilization of lignin is critical. $^{2}$

A major concern in utilizing lignin for the production of materials with consistent properties lies in the structural inhomogeneity of lignin itself. Lignin structure and properties vary depending on the wood species, the industrial processes utilized to isolate it, etc. ${ }^{3}$ Kraft lignin is generated in an amount of $\sim 50$ million tons per year as a by-product in the sulfate (kraft) wood-pulping process. ${ }^{4}$ During pulping, around 90 $95 \%$ of the lignin contained in the wood is degraded and dissolved in the aqueous solution of sodium hydroxide and sodium sulfide together with carbohydrate degradation products forming black liquor. Lignin is degraded into fragments of different molecular weights, which are soluble in alkaline solution. ${ }^{5}$

This article was published online on 21 April 2014. An error was subsequently identified. This notice is included in the online and print versions to indicate that both have been corrected 21 May 2014.

(c) 2014 Wiley Periodicals, Inc. 
Commercially, kraft lignin plays a vital role in pulp and paper manufacturing as a part of the chemical recovery process. The chemical recovery boiler of a kraft pulp mill is its largest investment; however, it is often the bottleneck in production. Lignin accounts for about $35 \%$ of the total dry solids of the black liquor and is also the main contributor to its heat value. Since the capacity of the recovery boiler is often limited by the heat load, the throughput of black liquor cannot be increased. In chemical pulp mills, where the recovery boiler is a bottleneck for increased production of fiber, lignin can, however, be extracted and used as external fuel or in more advanced polymeric applications. $^{6-10}$

Kraft lignin has several characteristic features that distinguish it from native lignin and other technical lignins: it contains a larger amount of phenolic groups due to the extensive cleavage of $\beta$-aryl bonds during kraft pulping, and some biphenyl units, as well as other condensed structures as a result of the severe cooking conditions. ${ }^{11}$ The weight-average molecular weight of kraft lignin obtained from black liquor can vary from about 600 to $180,000 \mathrm{Da}^{12}$ Consequently, the main limitation for the use of kraft lignin in value-added applications is its poor quality with respect to its non-homogeneous molecular weight distribution, the impurities originating from both the wood itself and process elements, and the varying amount of functional groups, resulting in reactivity differences.

Molecular mass is the key parameter affecting the reactivity and thermo-mechanical behavior of lignin, and fractionation is therefore a necessary step in order to obtain lignin with a narrow distribution of properties. ${ }^{13-15}$ Different methods have been suggested to fractionate lignin, including successive extraction with organic solvents, ${ }^{12,16}$ selective precipitation, ${ }^{17-19}$ and ultrafiltration. ${ }^{20-25}$ Toledano et al. $^{24}$ have shown in their comparative study that ultrafiltration gives the best results, as the lignin obtained is less contaminated with hemicelluloses. Ultrafiltration also allows a more efficient control of the molecular mass distribution of the lignin by the choice of suitable membrane cut-offs. These are important prerequisites with respect to the application of lignin in the polymeric field, and especially for the use of lignin as a precursor for carbon fiber production..$^{26-28}$ It has been stated that ultrafiltration is economically feasible on an industrial scale. ${ }^{29}$ A further major advantage of this method for the separation and fractionation of kraft lignin is the possibility to withdraw and use the black liquor at any position in the mill process without the need for $\mathrm{pH}$ or temperature adjustment.

By systematically characterizing the fractions obtained using the ultrafiltration approach, by investigation of lignin macromolecular properties, determination of key functional groups, as well as thermo-mechanical properties and reactivity, a technological platform for the targeted isolation of lignin fractions exhibiting the tailored properties necessary for specific applications can be developed. To the best of our knowledge, no systematic study has been performed so far to investigate the suitability of the ultrafiltration technique as a means for isolating fractions of technical kraft lignin with controlled thermo-mechanical properties.

In the present study, we have isolated lignin fractions with narrow molecular weight distributions by ultrafiltration of indus-

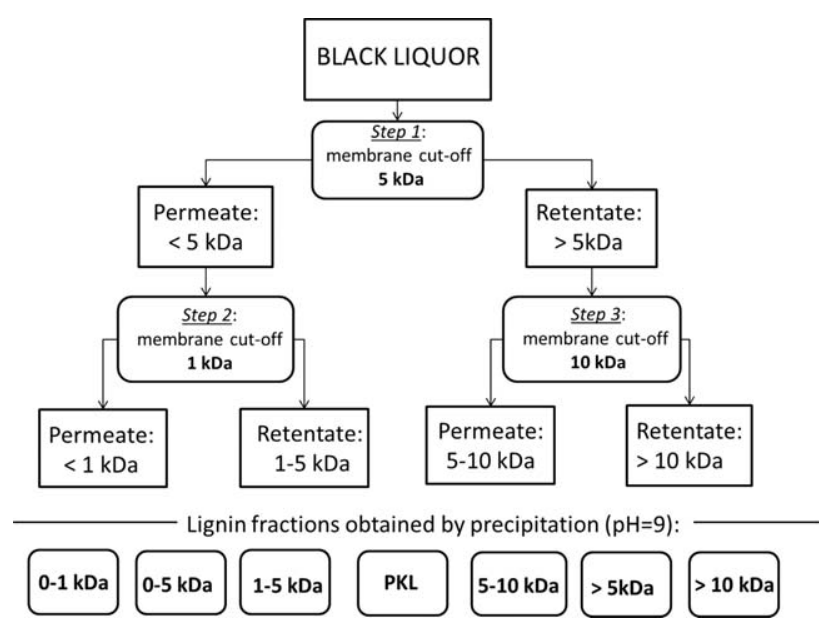

Figure 1. Experimental scheme for the fractionation and isolation of lignin fractions from industrial black liquor by ultrafiltration.

trial softwood weak black liquor, using membranes with molecular weight (MW) cut-offs of 1, 5, and $10 \mathrm{kDa}$. Detailed investigations of the composition, molecular weight, functional groups, as well as thermal and viscoelastic properties have been carried out for each lignin sample to investigate the efficiency of the ultrafiltration method for the fractionation of kraft lignin and to evaluate the potential of various lignin fractions for advanced polymeric applications, in particular for those where the melt-flow is required as the first step.

\section{MATERIALS}

Industrial softwood weak kraft black liquor was kindly supplied by the pulp and paper mill Billerud Gruvön, Sweden. The weak black liquor was taken prior to the evaporators. The $\mathrm{pH}$ was $>13$ and the solids content was $\sim 17.6 \%$. The liquor was used without $\mathrm{pH}$ adjustment.

\section{METHODS}

\section{Ultrafiltration}

Cross-flow filtration (or ultrafiltration, UF) was performed with pilot-scale membrane equipment. The system consists of a $30 \mathrm{~L}$ tank equipped with a stirrer, a heating element, a gear pump, and a membrane unit Kerasep ${ }^{\mathrm{TM}}$ (Novasep, Pompay, France). The membranes used in the study were ceramic membranes made of $\mathrm{TiO}_{2}$ and $\mathrm{ZrO}_{2}$ with a surface area of $816 \mathrm{~cm}^{2}$, suitable for the filtration of solutions with $\mathrm{pH}$ values between 0 and 14 at high pressures and high temperatures. Two membranes with 1 and $5 \mathrm{kDa}$ cut-offs were used. All experiments were carried out with a total recirculation of the black liquor. The temperature range was $40-65^{\circ} \mathrm{C}$, the trans-membrane pressure was $\sim 3.5$ bar and the pump velocity was $18.3 \mathrm{~L} / \mathrm{min}$. For the $10 \mathrm{kDa}$ separation, a bench-scale solvent-resistant stirred cell with working volumes of 10-300 $\mathrm{mL}$ and a regenerated cellulose membrane with $\mathrm{Mw}$ cut-off $10 \mathrm{kDa}$ from Millipore were used. The pressure was $0.35 \mathrm{MPa}$ and the filtration was run at room temperature.

A starting volume of $14 \mathrm{~L}$ of softwood weak black liquor was processed according to the scheme shown in Figure 1. In the first step, the pilot system equipped with a ceramic membrane having a $5 \mathrm{kDa}$ cut-off was used for ultra-filtration of the black liquor, 
which resulted in a volume reduction (VR) of about 0.7 (i.e., permeate volume divided by initial feed volume) and a volume reduction factor (VRF) of 3.5 (i.e., initial feed volume divided by the retentate volume). In the second step, the permeate from the first step was further fractionated using a ceramic membrane with a $1 \mathrm{kDa}$ cut-off, which resulted in a VR of about 0.6 corresponding to a VRF of 2.5. In the third step, the retentate from the first step was further fractionated in a stirred cell with a membrane having a $10 \mathrm{kDa}$ cut-off, which resulted in a VR of about 0.7 and a VRF of 3.2. In total, six liquid samples were obtained in addition to the original weak black liquor. All the samples were stored at $4^{\circ} \mathrm{C}$ prior to lignin isolation.

\section{Lignin Isolation and Purification}

Lignin samples were precipitated by acidifying the corresponding liquors to $\mathrm{pH} 9$ with $6 \mathrm{M}$ sulfuric acid. The high molecular weight liquors $(>5 \mathrm{kDa})$ were heated to $70^{\circ} \mathrm{C}$. The low molecular weight fractions $(<5 \mathrm{kDa})$ were precipitated following in general the procedure of Helander et al. ${ }^{25}$ Prior to NMR analysis, lignin samples were further purified by consecutive extraction with toluene and pentane. In total, seven lignin samples were obtained, including a lignin directly precipitated from the original weak black liquor (PKL). The different fractions are referred to as PKL (unfractionated lignin), $>10 \mathrm{kDa},>5 \mathrm{kDa}$, 5-10 kDa, 0-5 kDa, 1-5 kDa, and 0-1 kDa (Figure 1).

In ultrafiltration, the separation of solutes is defined by the molecular weight cut-off of the membrane used. The yield of specific fractions, thus, will depend on the type of the black liquors: on the amounts of high and low molecular weight kraft lignin present it. Since the yield of the material separated by UF do not correlate with molecular weight cut-offs of membranes, the yields of lignin fractions were not recorded in this study. Instead, focus was placed on the correlation between the MW cut-offs of membranes and the molecular weight of lignin fractions, their composition, structure, and properties. ${ }^{7,8,21,23,24}$

\section{Chemical Composition of Lignin Samples}

The solids content was determined using an infrared dryer balance PM460 (Mettler, Switzerland). The ash content was determined according to the ISO 1762. Elemental analysis $(\mathrm{C}, \mathrm{H}, \mathrm{N}$, and $\mathrm{S}$ ) was performed using 1-3 $\mathrm{mg}$ samples dried in a vacuum oven at $40^{\circ} \mathrm{C}$ for $48 \mathrm{~h}$, using a Flash EA 1112, Thermo Finnigan, USA elemental analyzer (external service provided by the Elemental Analysis Unit of the Santiago de Compostela University, USC, Santiago de Compostela, Spain). Klason lignin and carbohydrate analyses were performed according to TAPPI 222 om-02 and SCAN-CM 71:09. The sugar content was determined by an ion exchange chromatography (IC) with a Dionex ICS3000, using a pulsed amperometric detector, a PA1 column (Dionex, Stockholm, Sweden), injection volume $10 \mu \mathrm{L}$ and a flow rate of $1 \mathrm{~mL} / \mathrm{min}$. Carbohydrate standards used for calibration were arabinose, galactose, glucose, xylose, and mannose (Sigma-Aldrich, St. Louis, MO). The acid-soluble lignin content was determined according to Dence, ${ }^{30}$ where the acid-soluble lignin was analyzed with Shimdazu dual beam UV-2550 UV/VIS spectrophotometer (Kyoto, Japan) using quartz cuvettes. Acidsoluble lignin concentrations were determined using a lignin extinction coefficient (absorptivity) of $128 \mathrm{~L} / \mathrm{g} \cdot \mathrm{cm} .^{31}$

\section{Determination of Molecular Weight by Gel-Permeation Chromatography}

Molecular weight properties, such as the weight-average molecular weight $\left(M_{w}\right)$, the number-average molecular weight $\left(M_{n}\right)$, and the polydispersity index (PDI) of the isolated lignin fractions were determined by gel-permeation chromatography (GPC) according to Guerra et al. ${ }^{32}$ All samples were acetobrominated prior to analysis: a $5 \mathrm{mg}$ sample was stirred for $2 \mathrm{~h}$ at room temperature in $1 \mathrm{~mL}$ of a $9 / 1(\mathrm{v} / \mathrm{V})$ mixture of glacial acetic acid and neat acetyl bromide before surplus reagents were removed rapidly in vacuo. The residue was dissolved in $1 \mathrm{~mL}$ of HPLC grade tetrahydrofuran (THF), and the resulting solution filtered through a $5 \mu \mathrm{m}$ syringe filter to remove any eventually remaining solids. A $25 \mu \mathrm{L}$ aliquot was injected into a $20 \mu \mathrm{L}$ sample loop. GPC analysis was performed using a Shimadzu instrument consisting of a controller unit (CBM-20A), a pumping unit (LC 20AT), a degasser unit (DGU-20A3), and a diode array detector (SPD-M20A); the instrumental set-up was controlled using the Shimadzu LC solution software package (Version 1.24 SP1). Two analytical GPC columns (each $7.5 \times 30$ $\mathrm{mm}$ ) were connected in series for analyses: Agilent PL-gel $5 \mu \mathrm{m}$, $500 \AA$, followed by Agilent PL-gel $5 \mu \mathrm{m}, 1000 \AA$. HPLC-grade THF was used as solvent for sample preparation and GPC analyses. The flow rate was kept constant at $0.5 \mathrm{~mL} / \mathrm{min}$ during the analyses, and the UV signal was recorded for $60 \mathrm{~min}$. Calibration was performed using polystyrene beads with molecular weights of 50,400, 21,000, 7200, 2960, 1270, and 580 Da. The final analysis of each sample was performed using the intensities of the UV signal at $280 \mathrm{~nm}$ employing a MS-Excel-based table calculation.

\section{Functional Group Analysis by Quantitative ${ }^{31} \mathrm{P}$ NMR}

Phosphorus-31 Nuclear Magnetic Resonance $\left({ }^{31} \mathrm{P}\right.$ NMR) analysis with $90^{\circ}$ pulse angle, an inverse gated proton decoupling, and a delay time of $10 \mathrm{~s}$ was used for the identification and quantification of hydroxyl and carboxyl groups. Prior to analysis, a $20-25 \mathrm{mg}$ sample of the respective lignin fraction was functionalized using 2-chloro-4,4,5,5-tetramethyl-1,3,2dioxaphospholane in a $1 / 1.6$ mixture $\left({ }_{\mathrm{v}} / \mathrm{V}\right)$ of $\mathrm{CDCl}_{3}$ and pyridine for $2 \mathrm{~h}$ at room temperature. ${ }^{33}$

\section{Thermal Analysis and Dynamic Rheology}

Thermo-gravimetric analysis (TGA) was performed using a TA Instruments Q500 TGA. The decomposition temperature $\left(T_{d}\right)$ was determined by heating the samples from 25 to $500^{\circ} \mathrm{C}$ at a heating rate of $10^{\circ} \mathrm{C} / \mathrm{min}$ under a dry nitrogen $\left(\mathrm{N}_{2}\right)$ atmosphere. The $T_{d}$ of each sample was reported as the temperature at which there was a $5 \%$ weight loss. The glass transition temperature $\left(T_{g}\right)$ was determined using a TA Instrument Q1000 DSC at a scan rate of $10^{\circ} \mathrm{C} / \mathrm{min}$ over a temperature range from $0^{\circ} \mathrm{C}$ to $180-250^{\circ} \mathrm{C}$ (depending on the specimen). All measurements were made using $2-3 \mathrm{mg}$ samples placed in aluminum hermetic pans under a nitrogen atmosphere. $T_{g}$ was recorded at the midpoint temperature of the heat capacity transition of the second heating run. The results for each sample were reported as the average of 3 runs.

Viscoelastic responses of selected lignin samples were analyzed using a TA Instruments AR2000 dynamic torsional rheometer 


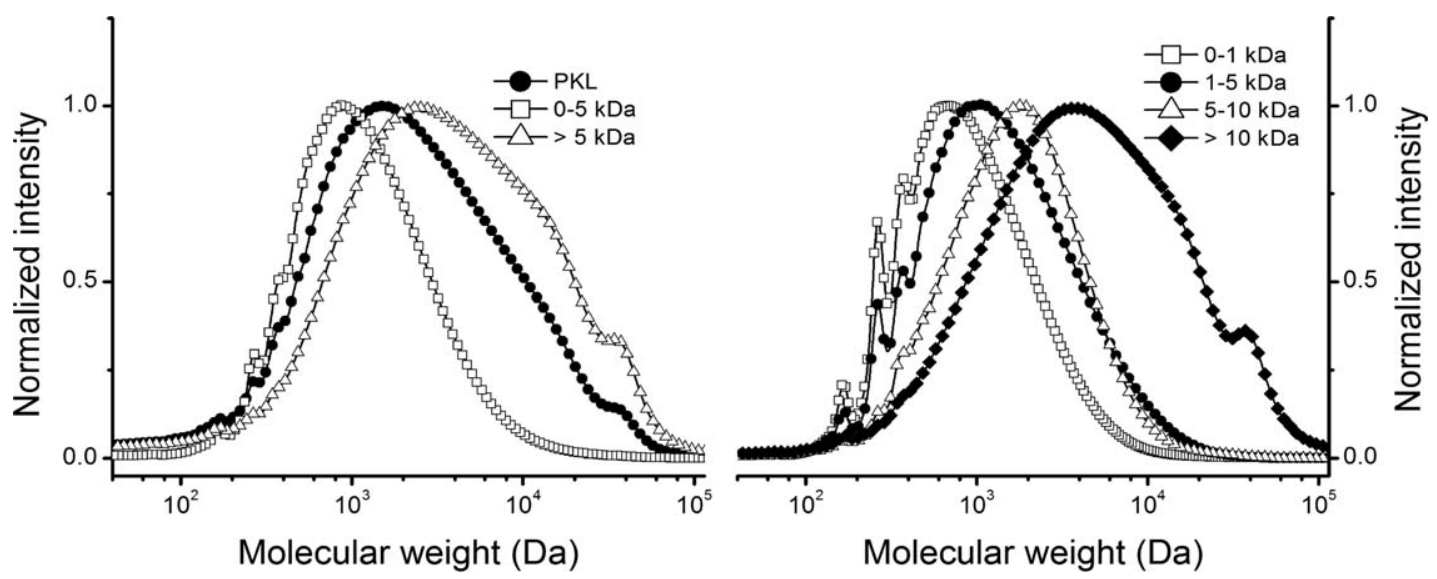

Figure 2. Molecular weight distribution curves obtained by GPC analysis for lignin fractions obtained by ultrafiltration of industrial black liquor. GPC measurements were performed using acetobrominated samples.

in the compression torsion mode. Details of this technique, and its advantages and limitations are described elsewhere. ${ }^{34}$ About $0.1 \mathrm{~g}$ of dry lignin powder was loaded between two parallel plates of $25 \mathrm{~mm}$ in diameter and dynamically strained $(0.1 \%$ strain, $1 \mathrm{~Hz}$ frequency) with increasing temperature at a rate of $3^{\circ} \mathrm{C} / \mathrm{min}$. Temperature-dependent viscoelastic responses were analyzed by sequential heat-cool-heat cycles as following: (1) heating from room temperature to $160-200^{\circ} \mathrm{C}$ (depending on the specimen), (2) cooling to room temperature, (3) heating to $250^{\circ} \mathrm{C}$. All experiments were conducted in a dry $\mathrm{N}_{2}$ atmosphere. The glass transition temperature was determined as the peak maximum of the loss modulus $\left(G^{\prime \prime}\right)$ for both heating steps.

\section{RESULTS AND DISCUSSIONS}

\section{Effect of Ultrafiltration on the Molecular Weight of Lignin Fractions}

The efficiency of the ultrafiltration approach for fractionating lignin from the kraft black liquor and obtaining a material with specific characteristics was evaluated by studying the molecular weight properties of lignin fractions.

Over the years, several SEC/GPC procedures were examined and suggested for the determination of the molecular mass of lignin samples of various type and origins. ${ }^{35-39}$ In the recent Round Robin effort to standardize SEC analysis of technical lignins undertaken within the European thematic network "Eurolignin" it was shown that high-molecular-mass fractions of polydisperse lignins are the main source of intra- and interlaboratory variations. ${ }^{40}$ Variations mainly resulted from the gel type used for separation, the eluent, the detection mode and the mode of analyzing. Incomplete solubility of lignin samples prior to GPC analysis was found to be a serious source of error. To reduce the variations, crosslinked polyvinyl styrene columns, THF as the mobile phase, and acetylation as the derivatization method were suggested, and it was recommended that the acetylation should be conducted over a period of 6 days (room temperature) to ensure complete dissolution. ${ }^{40}$ In the present work, in order to investigate the efficiency of the fractionation of lignin samples obtained by ultrafiltration, we followed a GPC analysis using an acetobromination as derivatization procedure as suggested by Guerra et al. ${ }^{32}$ The main advantage of this method is the comparably short reaction period, which minimizes any structural alterations, and yields lignin derivatives that are highly soluble in $\mathrm{THF}^{41,42}$ It has been shown that molecular masses observed when the acetobromination derivatization is used, which are comparable to those obtained with acetic anhydride in pyridine derivatization. ${ }^{42}$

The molecular weight distribution curve (Figure 2) for the 0-1 $\mathrm{kD}$ lignin sample had a number of peaks in the low molecular weight (MW) region, as shown in Figure $2 \mathrm{~b}$. The same peaks were found in the $1-5 \mathrm{kDa}$ and $0-5 \mathrm{kDa}$ samples, with lower relative intensities. The presence of these similar lignin fragments in both samples, albeit in different quantities, indicates that small amounts of low molecular weight fragments (monoand dimers) are present in the low molecular weight lignin fractions. A similar phenomenon was observed in the high molecular weight region: the chromatograms for the reference sample PKL and the two high-molecular weight samples, $>5 \mathrm{kDa}$ and $>10 \mathrm{kDa}$, all showed a peak at the same position in a very high MW range (at around $50-60 \mathrm{kDa}$ ). These peaks may correspond to LCC complexes of very high molecular weight present in the lignin samples. These samples had a higher carbohydrate content, as shown in Table II and discussed below.

The $M_{w}, M_{n}$, and PDI for the acetobrominated lignin samples are shown in Table I and illustrate a quite efficient fractionation of lignin based on the molecular size. There is a clear decrease in weight-average molecular weight with decreasing molecular weight cut-offs of the membranes used for the fractionation. The $M_{w}$ value seems to be in a good agreement with cut-offs of the membranes. Polydispersities of lignin fractions were reduced as a result of fractionation, indicating that ultrafiltration results in more homogeneous materials with narrower molecular weight distributions.

It is difficult to compare our results with data available in the literature due to the nature of the lignin samples ${ }^{3,4}$ and the uncertainties related to the GPC analysis itself. ${ }^{40}$ For unfractionated softwood kraft lignin, a $M_{w}$ value of 39,000 was reported earlier. ${ }^{13}$ Toledano et al. ${ }^{24}$ reported an efficient fractionation of lignin using an ultrafiltration technique with ceramic 
Table I. Weight-Average $\left(M_{w}\right)$, Number-Average $\left(M_{n}\right)$ Molecular Weights and Polydispersity Index (PDI) of Different Fractions Obtained by Ultrafiltration $^{\mathrm{a}}$

\begin{tabular}{llll}
\hline Samples & $M_{w}$ & $M_{n}$ & PDI \\
\hline PKL & 20,200 & 5000 & 4.1 \\
$>10$ & 33,500 & 9500 & 3.5 \\
$>5$ & 28,200 & 8000 & 3.5 \\
$5-10$ & 4900 & 2300 & 2.2 \\
$1-5$ & 4700 & 2000 & 2.3 \\
$0-5$ & 4100 & 1700 & 2.4 \\
$0-1$ & 2700 & 1200 & 2.1 \\
\hline
\end{tabular}

a The molecular weights are relative values, related to polystyrene standards, and were obtained from GPC measurements of acetobrominated samples.

membranes of cut-offs 5, 10, and $15 \mathrm{kDa}$ on black liquor from the pulping of Miscanthus sinensis. GPC data presented in that paper; however, report quite low $M_{w}$ values for lignin fractions isolated with membranes having cut-offs of 10 and $15 \mathrm{kDa}$ : 3500 and $6300 \mathrm{Da}$, respectively. This can be the result of a poor solubility of the lignin samples during the GPC analysis when acetylation was used as derivatization procedure.

\section{The Composition and the Chemical Structure of the Lignin Fractions}

Beside the molecular weight characteristics of lignin, its purity and structure, i.e., the presence of reactive functional groups, are key factors determining the utility of lignin for value-added applications. In the present study, we used traditional Klason lignin and carbohydrate analyses, in combination with elemental analysis, to evaluate the purity of the lignin fractions obtained by ultrafiltration and subsequent precipitation with acid. The number of the various functional groups was determined using quantitative ${ }^{31} \mathrm{P}$ NMR spectroscopy.

The compositions with respect to carbohydrates, Klason lignin, acid-soluble lignin, and inorganic impurities of the reference (PKL) and the fractionated lignin samples are shown in Table II.

All the samples have a low ash content, which indicates an acceptable acid wash. In general, the lignin materials obtained by ultrafiltration have a high purity with respect to carbohydrates, which is in good agreement with a previous study. ${ }^{24}$

Table II. Chemical Composition of PKL and Fractionated Lignin Samples

\begin{tabular}{lllll}
\hline Samples & $\begin{array}{l}\text { Carbohydrates } \\
(\%)\end{array}$ & $\begin{array}{l}\text { Klason } \\
\text { lignin (\%) }\end{array}$ & $\begin{array}{l}\text { Ash } \\
(\%)\end{array}$ & $\begin{array}{l}\text { Acid-soluble } \\
\text { lignin (\%) }\end{array}$ \\
\hline PKL & 1.7 & 96.9 & 0.1 & 2.0 \\
$>10$ & 5.2 & 94.4 & 0.2 & 1.0 \\
$>5$ & 3.4 & 94.9 & 0.5 & 1.2 \\
$5-10$ & 0.3 & 93.8 & n/a & 2.9 \\
$1-5$ & 0.2 & 97.8 & 0.2 & 3.7 \\
$0-5$ & 0.3 & 94.3 & 1.1 & 5.6 \\
$0-1$ & 0.1 & 97.2 & 2.2 & 5.7 \\
\hline
\end{tabular}

Only the high-molecular weight fractions, $>10 \mathrm{kDa}$ and $>5 \mathrm{kDa}$, contain a noticeable amount of sugars, in the range of $3-5 \%$. It is reasonable to assume that the carbohydrates detected are part of lignin-carbohydrate complexes (LCC). It has previously been reported that most of the lignin present in wood, and especially in the pulp, exists in form of LCC's with various types of hemicelluloses. ${ }^{43,44}$ During the kraft cooking, severely degraded low molecular weight fragments of the lignin macromolecule are dissolved in the pulping liquor.

As the ultra-filtration technique allows the fractionation of dissolved material based on its molecular weight, the fraction of molecular size $>10 \mathrm{kDa}$ (for the industrial liquor investigated in this study) contains a large amount of carbohydrates. The 5-10 kDa lignin sample contains only traces of sugars, which means that contamination in the $>5 \mathrm{kDa}$ sample was due to the lignin material with a molecular weight greater than $10 \mathrm{kDa}$ (Table I). As expected, low molecular weight lignin fractions contain larger proportions of acid-soluble lignin. This is in the agreement with previous studies. ${ }^{25}$

The Klason lignin analysis shows that the lignin fractions have high lignin content (Table II). Elemental analysis (Table III) shows; however, that the low MW lignin fractions $0-1 \mathrm{kDa}$ and $0-5 \mathrm{kDa}$, respectively, contain $23-27 \%$ of sulfur, which coprecipitated with the lignin during acidic hydrolysis. It is not clear whether this sulfur comes from the cooking chemicals or was incorporated into the lignin molecules during the kraft cooking. Successive extraction with toluene and pentane removed most of the sulfur, giving lignin materials with sulfur contents in the range between 1.6 and $4.8 \%$; a complete removal of sulfur; however, cannot be achieved in this way. Independent of the washing procedure, there is a trend towards high sulfur contents in lower molecular weight fractions (Table III).

${ }^{31} \mathrm{P}$ NMR data (Table IV) show that the unfractionated lignin, PKL, has a high number of phenolic hydroxyl and aliphatic hydroxyl groups, which is a known feature of kraft lignins. A significant number of phenolic groups in technical kraft lignin provides high reactivity and thus makes the kraft lignin an attractive biopolymer for utilization in various applications. Ultrafiltration has shown; however, that kraft lignin in black liquor is nonhomogeneous not only with respect to its molecular size, but also with respect to the quantity of functional groups. With increasing molecular size, the different lignin fractions tend to exhibit an increasing number of aliphatic hydroxyl groups, and a decreasing amount of phenolic hydroxyl groups. The content of carboxylic groups was not affected by the fractionation, i.e., not dependent on the molecular size of the isolated lignin fractions. These observations are in accordance with the mechanism of lignin degradation during kraft cooking. The formation of low molecular weight fractions could be the result of a breakdown of the linkages during kraft cooking; more free phenolic groups - in relation to aliphatic hydroxyl groups-are present in these fractions. This could also be the reaction leading to higher amounts of sulfur with decreasing molecular weight of lignin. The high molecular weight lignin fractions, on the other hand, probably preserved more side chains and $\beta$-O-4 linkages, and hence exhibit less free phenolic and comparably 
Table III. Elemental Composition of PKL and Fractionated Lignin Samples

\begin{tabular}{|c|c|c|c|c|c|c|c|c|}
\hline \multirow[b]{2}{*}{ Samples } & \multicolumn{4}{|c|}{ Before extraction (\%) } & \multicolumn{4}{|c|}{ After extraction (\%) } \\
\hline & S & $\mathrm{N}$ & $\mathrm{C}$ & $\mathrm{H}$ & S & N & $\mathrm{C}$ & $\mathrm{H}$ \\
\hline$\overline{P K L}$ & 2.5 & 0.1 & 64.9 & 5.5 & 1.8 & 0.1 & 64.7 & 5.9 \\
\hline$>10$ & 1.7 & 0.1 & 62.3 & 5.1 & 1.6 & 0.1 & 62.1 & 5.9 \\
\hline$>5$ & 1.8 & 0.1 & 64.9 & 5.3 & 1.6 & 0.1 & 63.5 & 5.8 \\
\hline $5-10$ & 2.0 & 0.1 & 62.6 & 5.4 & 1.7 & 0.1 & 65.1 & 6.0 \\
\hline $1-5$ & 7.2 & 0.1 & 62.1 & 5.4 & 3.0 & 0.1 & 68.5 & 6.4 \\
\hline $0-5$ & 23.0 & 0.1 & 51.6 & 4.8 & 4.0 & 0.1 & 66.1 & 6.3 \\
\hline $0-1$ & 27.1 & 0.1 & 48.9 & 4.2 & 4.8 & 0.1 & 63.4 & 5.9 \\
\hline
\end{tabular}

more aliphatic hydroxyls. The higher content of carbohydrates in the high MW fraction may also contribute to the observed increased content of aliphatic hydroxyls. These results are in a good agreement with previous findings based on quantitative HSQC NMR studies of kraft lignin samples obtained by a solubility-based fractionation. ${ }^{45}$

\section{Thermal Behavior of Kraft Lignin Fractions: Role of Molecular Weight and Structure}

Thermal analyses such as TGA and differential scanning calorimetry, DSC, are useful methods for studying the physicochemical properties of polymers. As vaporization, chemical reactions and thermal degradation are accompanied by a weight loss, TGA can be a useful tool for elucidating the physicochemical properties of lignin. However, for isolated lignins, overall degradation is a very complex process involving the simultaneous formation/degradation of several interunit linkages, and this makes the interpretation of TGA spectra of lignins ambiguous. In the present study, we used the TGA method to compare the thermal stabilities of the lignin fractions. The thermal analysis by TGA reveals significant differences in decomposition temperatures $\left(T_{d}\right)$, defined by $5 \%$ of weight-loss of dry samples, between the lignin fractions as shown in Figure 3 and Table V.

The decomposition temperature generally increased with increasing molecular weight, with exception of the $5-10 \mathrm{kDa}$ sample. The decomposition temperature of this sample was $240^{\circ} \mathrm{C}$, which is higher than that of the two samples with higher

Table IV. Content of Functional Groups in PKL and Fractionated Lignin Samples

\begin{tabular}{llll}
\hline Samples & $\begin{array}{l}\text { Aliph-OH } \\
(\mathrm{mmol} / \mathrm{g})\end{array}$ & $\begin{array}{l}\mathrm{Ph}-\mathrm{OH} \\
(\mathrm{mmol} / \mathrm{g})\end{array}$ & $\begin{array}{l}-\mathrm{COOH} \\
(\mathrm{mmol} / \mathrm{g})\end{array}$ \\
\hline $\mathrm{PKL}$ & 2.25 & 3.50 & 0.36 \\
$>10$ & 2.62 & 2.81 & 0.52 \\
$>5$ & 2.33 & 2.95 & 0.49 \\
$5-10$ & 1.88 & 3.87 & 0.49 \\
$1-5$ & 1.37 & 3.70 & 0.35 \\
$0-5$ & 1.42 & 3.61 & 0.46 \\
$0-1$ & 1.25 & 4.11 & 0.38 \\
\hline
\end{tabular}

molecular weight, i.e., $>10$ and $>5 \mathrm{kDa}$ (Figure 3 ). The 5-10 $\mathrm{kDa}$ sample is the purest lignin sample as it contains less sulfur than the $0-1,0-5$, and $1-5 \mathrm{kDa}$ fractions, and less carbohydrates than the high-molecular weight fraction $(>5 \mathrm{kDa},>10$ $\mathrm{kDa}$ ) and the unfractionated lignin. This lignin fraction also has a low polydispersity (PDI 2.2), which is comparable to those of the lower MW fractions. All these factors probably resulted in the observed higher thermal stability.

The $T_{g}$ of lignin is affected by factors such as molecular weight in the first place, but also by the thermal history, by the presence of low molecular weight contaminants (including water and solvents), and by crosslinking. In conventional DSC studies, the glass transition temperature $\left(T_{g}\right)$ of a polymer is obtained from the second heating scan, while the initial scan (above its $T_{g}$ ) is usually used to eliminate the thermal history stored within the polymer's glassy state. ${ }^{46,47}$ Kraft lignin with its amorphous nature and its propensity for hydrogen bonding interactions usually exhibits a significant enthalpy relaxation resulting in a broad endothermic peak covering its glassy region during the initial heating period in the DSC scan (Figure 4, 1st heat).

To compare the lignin fractions in the present study, heating to $150^{\circ} \mathrm{C}$ was selected as the annealing temperature for all samples. This choice was based on the fact that this temperature is expected to be above the $T_{g}$ for most of the lignin samples. The DSC heating curves between the 1st and 2nd heating scans are shown in Figure 4. Heat flow curves from the 1st heating run for most samples have a shape typical for lignin, except for the low MW fractions $0-1 \mathrm{kDa}$ and $0-5 \mathrm{kDa}$. These two samples exhibit two obvious transition regions below the $T_{g}$ of lignin as well as an endothermic peak at $117^{\circ} \mathrm{C}$. The first transition is predominant and occurs between 50 and $60^{\circ} \mathrm{C}$. This transition may be associated with the relaxation of lignin segments that are plasticized by trace amounts of nonbonded water. On the other hand, the smaller transition observed at around $100^{\circ} \mathrm{C}$ could be associated with changes in lignin molecules caused by evaporation of bonded water. ${ }^{48}$ These two transitions are less obvious in other lignin fractions as they are covered by a broad endothermic peak resulting from the lignin enthalpy relaxation process. The transitions and peaks at $117^{\circ} \mathrm{C}$ were eliminated as a result of the 1st heating scan. The major difference between these two low MW fractions and the rest of the samples is their significantly higher sulfur content, which leads to the 


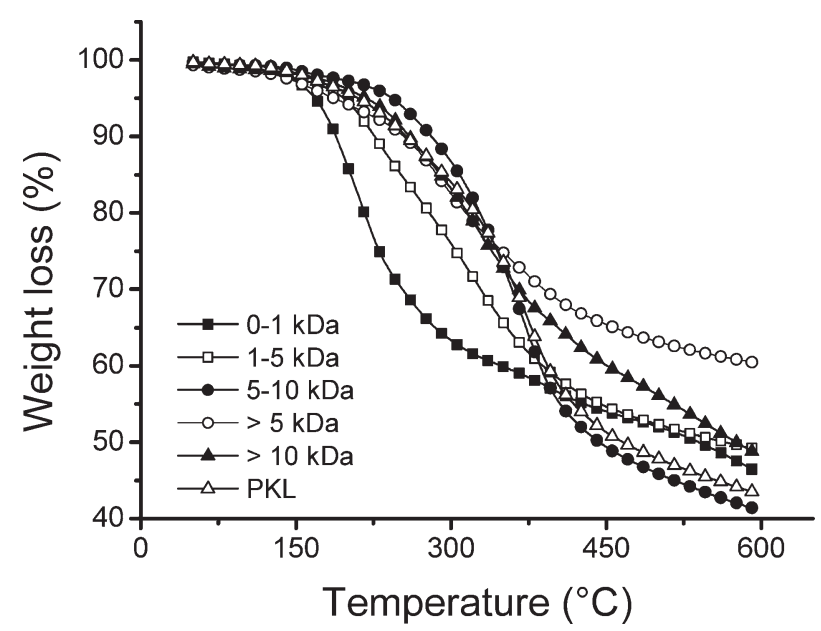

Figure 3. Result of thermo-gravimetrical (TGA) analysis of lignin fractions. Decomposition temperature was estimated at $5 \%$ of weight loss.

conclusion that the endothermic peaks in the initial DSC scan are probably due to the presence of low molecular weight sulfur-containing compounds in addition to traces of water. The $T_{g}$ 's of the lignin fractions were determined as the midpoint of the heat transition of the 2 nd heating run, after the thermal history of sample had been eliminated (Figure 4 and Table V).

Table $\mathrm{V}$ summarizes the decomposition and transition temperature data obtained by the TGA, DSC, and dynamic rheology (DMA) for unfractionated lignin and lignin fractions obtained by the ultrafiltration of kraft black liquor. Three different $T_{g}$ measurement methods are demonstrated: as the midpoint of the heat capacity transition of the 2nd DSC heating scan, as a peak maximum of $\mathrm{G}$ and as a peak maximum of $\tan \delta$ for both 1 st and 2nd heating scans. The glass transition temperatures, $T_{g}$, obtained for the fractionated samples lie between $70^{\circ} \mathrm{C}$ and $170^{\circ} \mathrm{C}$ (Table $\mathrm{V}$ ). The reference sample, PKL, had a $T_{g}$ of $144^{\circ} \mathrm{C}$, while the $>10 \mathrm{kDa}$ sample had a $T_{g}$ of $170^{\circ} \mathrm{C}$ and the $0-1 \mathrm{kDa}$ sample has a $T_{g}$ of $70^{\circ} \mathrm{C}$. The dependence of $T_{g}$ on the molecular weight has been reported earlier for lignin samples obtained by the solvent fractionation

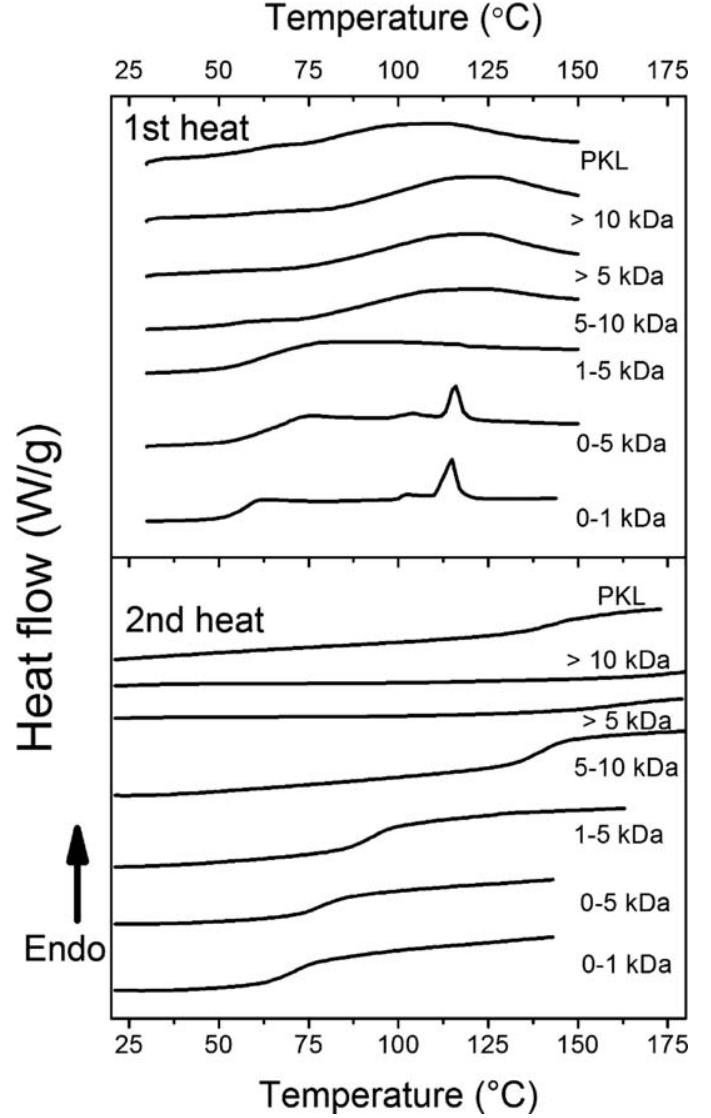

Figure 4. Heat flow curves on the 1st and 2nd heating scans of lignin fractions and PKL lignin measured by differential scanning calorimetry (DSC).

procedure, ${ }^{13}$ also indicating that $T_{g}$ is highly influenced by the morphology of the polymer. As molecular weight increases, the entanglement, and consequently the rigidity of the polymer increases, resulting in the increase of $T_{g}$. This trend can be explained by the well-known Fox-Flory equation, ${ }^{49,50}$ as will be described later in the article. This variation in $T_{g}$ of kraft lignins isolated from the same black liquor illustrate the potential of ultrafiltration for isolating a specific

Table V. Decomposition and Transition Temperature Data Obtained by the TGA, DSC, and Dynamic Rheology for Unfractionated Lignin and Lignin Fractions Obtained by the Ultrafiltration of Kraft Black Liquor

\begin{tabular}{|c|c|c|c|c|c|c|}
\hline \multirow[b]{3}{*}{ Samples } & \multirow{3}{*}{$\frac{\text { TGA }}{T_{d}\left({ }^{\circ} \mathrm{C}\right)}$} & \multirow{3}{*}{$\frac{\mathrm{DSC}}{T_{g}\left({ }^{\circ} \mathrm{C}\right)}$} & \multicolumn{4}{|c|}{ Dynamic rheology } \\
\hline & & & \multicolumn{2}{|c|}{ Peak maximum loss modulus $\left(G^{\prime}\right)$} & \multicolumn{2}{|c|}{ Peak maximum $\tan \delta$} \\
\hline & & & $\begin{array}{l}T_{g 1},\left({ }^{\circ} \mathrm{C}\right) \\
\text { (1st scan) }\end{array}$ & $\begin{array}{l}T_{g 2}\left({ }^{\circ} \mathrm{C}\right) \\
\text { (2nd scan) }\end{array}$ & $\begin{array}{l}T_{g 1},\left({ }^{\circ} \mathrm{C}\right) \\
\text { (1st scan) }\end{array}$ & $\begin{array}{l}\mathrm{T}_{\mathrm{g} 2}\left({ }^{\circ} \mathrm{C}\right) \\
\text { (2nd scan) }\end{array}$ \\
\hline $\mathrm{PKL}$ & 215 & 144 & 149 & 165 & 183 & 192 \\
\hline$>10$ & 217 & 170 & $\mathrm{n} / \mathrm{a}$ & $\mathrm{n} / \mathrm{a}$ & $\mathrm{n} / \mathrm{a}$ & $\mathrm{n} / \mathrm{a}$ \\
\hline$>5$ & 190 & 159 & 158 & 185 & 199 & 221 \\
\hline $5-10$ & 240 & 140 & 140 & 155 & 194 & 210 \\
\hline $1-5$ & 193 & 94 & 93 & 127 & 147 & 179 \\
\hline $0-5$ & 175 & 82 & 96 & 114 & 150 & 165 \\
\hline $0-1$ & 163 & 70 & 84 & 97 & 135 & 150 \\
\hline
\end{tabular}




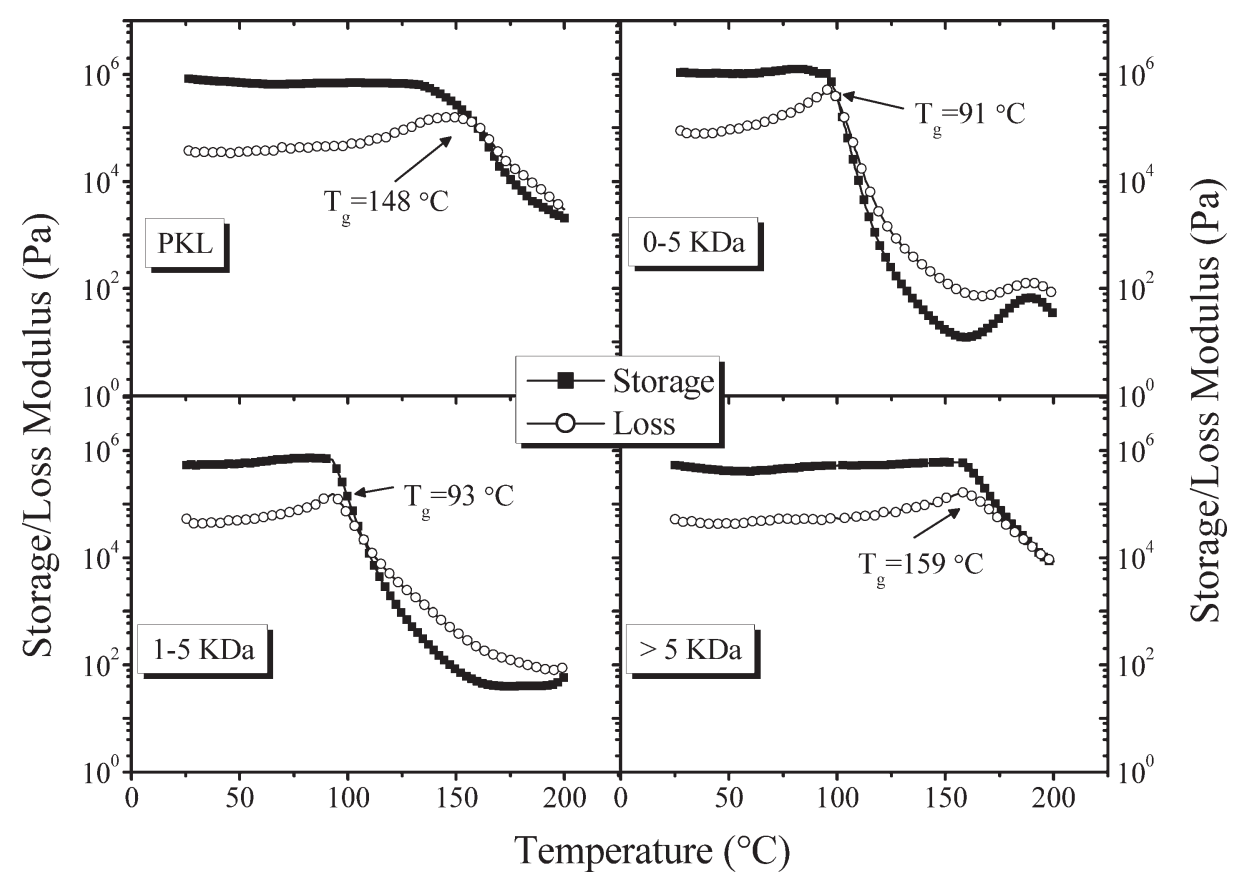

Figure 5. Dynamic rheological response of lignin powder of different molecular weight. First heat responses for unfractionated (PKL) and fractionated lignin (on the basis of MW) are demonstrated.

lignin fraction with the properties desirable for a certain application.

Although there is a clear tendency for $T_{g}$ to increase with molecular weight, the exact $T_{g}$ value for each fraction is quite ambiguous. This is due to the fact that nonreversible thermal events, such as condensation reactions, may take place in lignin molecules upon heating above the $T_{g}$ as a result of breakage of intermolecular hydrogen bonds and increased chain mobility. ${ }^{48,51}$ In their detailed study on the molecular understanding of the way in which the polymeric properties of kraft lignin are affected by various thermal treatments, Cui et al. ${ }^{51}$ have shown

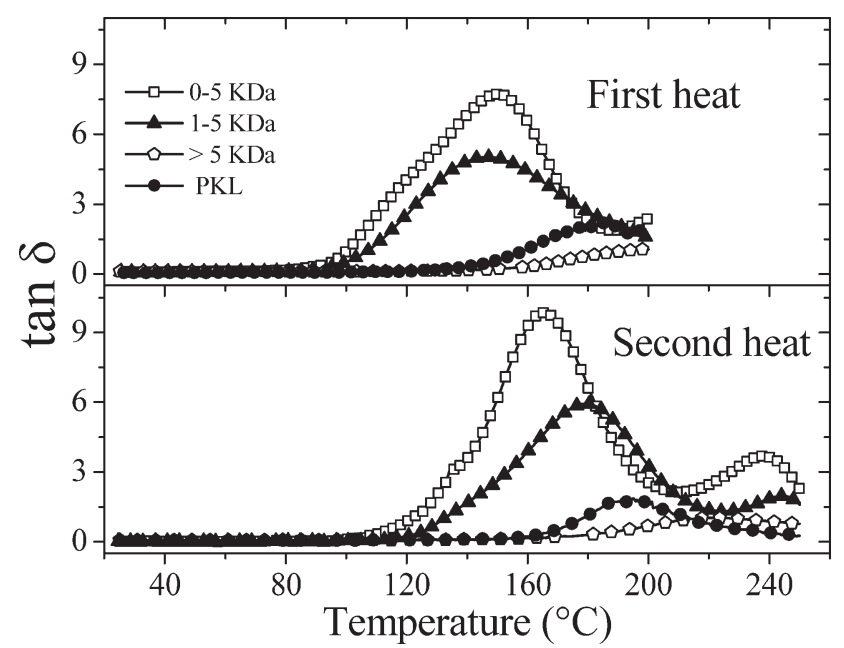

Figure 6. Dynamic rheological response of membrane separated lignin. First and second heat $\tan \delta$ for PKL (reference lignin) and lignin samples with varying molecular weights are shown. that a significant crosslinking through a radical coupling mechanism may take place in lignin molecules when they are heated to temperatures close to their $T_{g}$ s during the initial DSC scan. This may lead to an increase in molecular weight and polydispersity, resulting in a higher $T_{g}$ observed in the second DSC scan.

Viscoelastic Behavior and Crosslinking Tendency of Lignin Fractions

DMA analysis is known to be a more adept technique for polymer glass transition analysis. The viscoelastic responses of the dry lignin powders were thus studied using parallel-plate

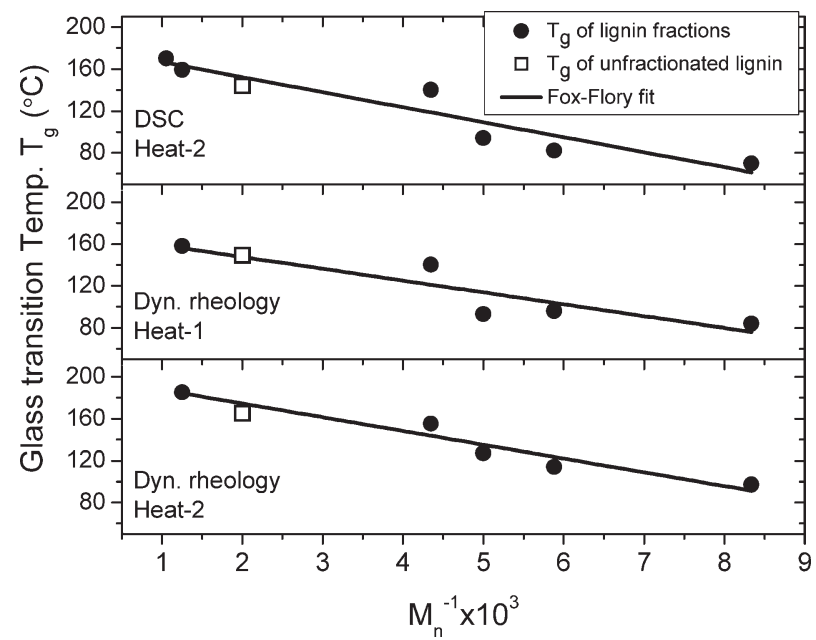

Figure 7. Fox-Flory plot for unfractionated and fractionated lignin. Glass transition temperature versus reciprocal of number average molecular weight are plotted. 
Table VI. Estimated Fox-Flory Parameters, Obtained from the Experimental $T_{g}$ from DSC and Dynamic Rheology

\begin{tabular}{llll}
\hline Method & Heating cycle & $T_{g \infty}\left({ }^{\circ} \mathrm{C}\right)$ & $k_{g}$ \\
\hline DSC & 2nd & 181 & $1.4 \times 10^{5}$ \\
Dynamic rheology & 1 st & 170 & $1.1 \times 10^{5}$ \\
Dynamic rheology & 2nd & 201 & $1.3 \times 10^{5}$ \\
\hline
\end{tabular}

dynamic torsional rheology (Figures 5 and 6). The temperaturedependent evolutions of the storage $\left(G^{\prime}\right)$ and the loss $\left(G^{\prime \prime}\right)$ moduli were observed. The molecular weight had a distinct effect on the viscoelasticity of lignin, especially the $T_{g}$ (identified from the peak of $G^{\prime \prime}$ ) and the degree of softening (identified as the change in $G^{\prime}$ across the glass transition). With increasing molecular weight, $T_{g}$ increased-indicating a trend similar to that shown by the DSC analysis (Figure 4 and Table V). Moreover, ${ }^{31} \mathrm{P}$ NMR data (Table IV) show that the higher molecular weight fractions had higher proportions of aliphatic $-\mathrm{OH}$ groups are compared to the lower MW fractions: aliphatic $-\mathrm{OH}$ groups are more capable of intermolecular hydrogen bonding and generate a greater mobility restriction. ${ }^{52,53}$

The lignin glass-rubber transition-the change in $G^{\prime}$ from the glassy to the rubbery phase-was associated with significant softening. Differences in the molecular weight clearly affected the degree of softening also. Unfractionated lignin (PKL) showed a drop in $G^{\prime}$ of one decade across the glass transition; lower molecular weight fractions softened more (up to a $G^{\prime}$ drop of 5 decades for $0-5 \mathrm{kDa}$ and $1-5 \mathrm{kDa}$ ) and the high molecular weight fraction hardly softened (a $G^{\prime}$ drop of less than 2 decades for the $>5 \mathrm{kDa}$ fraction) and never reached the rubbery plateau within the experimental temperature range. The absence of rubbery plateau for PKL and high MW fractions indicates that the lignin in high MW fractions are more condensed (have a higher effective crosslink density) than in the low MW fraction. This response is, again, rationalized on the basis of more efficient intermolecular hydrogen bonding in the high MW fractions because of the presence of more aliphatic hydroxyl groups in the lignin molecules as well as due to the presence of larger quantity of carbohydrates in them.

A rubbery plateau region is indicative of the effective crosslink density in the polymer. ${ }^{54} \mathrm{After}$ the drop that the storage modulus took in the glass transition region, it became almost constant for $1-5 \mathrm{kDa}$ sample within a temperature region between 150 and $200^{\circ} \mathrm{C}$. For the $0-5 \mathrm{kDa}$ lignin fraction an additional high-temperature crosslinking reaction was observed during the rubbery plateau phase indicated as a peak in $G^{\prime}$ at around $180^{\circ} \mathrm{C}$. This fraction has a higher amount of sulfur in it than high MW lignin and the $1-5 \mathrm{kDa}$ fraction, which could have some effect on increased reactivity. The loss modulus dominated in the rubbery plateau phase for these samples.

A lower crosslink density, as in case of the low MW fractions 0-5 $\mathrm{kDa}$ and $1-5 \mathrm{kDa}$, leads to a well-defined lower rubbery plateau modulus and a higher flow at high temperature. ${ }^{54}$ This is extremely important in the thermal processing of lignin, where melt-flow is required as the first step, e.g., fiber spinning. Higher flow is required for optimum melt extrusion and spinning.

Figure 6 shows the $\tan \delta$ of the first and second heat scans of the lignin samples. Although, $T_{\mathrm{g}}$ 's can be obtained from the peak of $G^{\prime \prime}$ (Figure 5), the peak of $\tan \delta$ also presents a popular way to determine $T_{g}$. The peak $\tan \delta$-temperature showed a prominent shift to a higher temperatures from the 1st to the 2nd heating scan, presumably due to the temperature-induced crosslinking of the lignin by aryl ether linkage formation between two phenylpropane units. ${ }^{48}$ It is also evident in the tan $\delta$ profile of 2 nd heating scan of the $0-5 \mathrm{kDa}$ sample that there is, again, another minor transition at around $240^{\circ} \mathrm{C}$. This is due to additional high-temperature crosslinking reaction. This transition is also weakly visible in the $1-5 \mathrm{kDa}$ specimen. Intriguingly, this high-temperature transition was not prominent in unfractionated and $>5 \mathrm{kDa}$ lignin fractions. This perhaps indicates a higher reactivity of the low MW lignin fractions, containing also higher amount of sulfur, than of the higher MW fraction. In unfractionated lignin, the higher molecular weight fraction dominated the viscoelastic responses and the additional high- temperature crosslinking was not visible.

The Fox-Flory equation is one of the most widely used relations to explain polymer glass transition dependence on molecular weight:

$$
T_{g}=T_{g \infty}-\frac{k_{g}}{M_{n}}
$$

where $T_{g}$ is the glass transition temperature of any fraction, $M_{n}$ : the number average molecular weight of that fraction; $T_{g \infty}: T_{g}$ of the material at infinite molecular weight; and $k_{g}$ : parameter explaining the molecular weight dependence of $T_{g}$ for the given material. $^{50,55,56}$

Figure 7 shows the fit for the $T_{g}$ values obtained from DSC and DMA according to the Fox-Flory equation; delineated FoxFlory parameters are compiled in Table VI.

Experimental $T_{g}$ data show a reasonable agreement with the Fox-Flory prediction (Figure 7), exhibiting coefficients of determination of 0.944 for DSC, 0.887 for DMA heat-1, and 0.966 for DMA heat-2. The observed scatter in the data is due to the differences in the chemical nature of the fractions that is not explained by the Fox-Flory relation, which only predicts the effects of molecular weight change on the $T_{g}$. The $T_{g}$ of unfractionated PKL sample lies within the regression in each case. $T_{g \infty}$ and $k_{g}$ provide an indication of the stiffness of the polymer chains and relates to the effective crosslink density; materials with higher $T_{g \infty}$ provide higher $k_{g}$, indicating a stiffer polymeric system. Furthermore, $k_{g}$ relates to the polarity and the abundance of chain ends; the lower the number of chain ends (i.e., higher crosslink density), the lower is the free volume, resulting in higher polymer stiffness. ${ }^{50}$ The DMA data show this trend. The 2 nd heat $T_{g \infty}$, as well as $k_{g}$ increase as compared to the corresponding 1 st heat parameters, reaffirming the increased crosslink density in lignin samples due to exposure to high temperatures.

The thermal analyses by DSC and DMA reveal significant differences in the glass-transition temperatures $\left(T_{g}\right)$ between the lignin 
fractions. At the same time, the tendency for $T_{g}$ increase with increased molecular weight is obvious for each applied method. The shift in $T_{g}$ to higher values from the 1st to the 2 nd heating run, measured from both, the G-peak and the $\tan \delta$ peak, were similar, indicating the validity of the applied detection techniques.

DMA is an efficient tool for evaluating the behavior of lignin samples during various thermal processing reactions, e.g., for screening the spinnability of a lignin sample and predict its spinning temperature, as will be described elsewhere (Chowdhury et al., unpublished results). ${ }^{57}$ It is evident based on the data presented in here, that the $0-5 \mathrm{kDa}$ and $1-5 \mathrm{kDa}$ molecular weight fractions, having good high-temperature flows and crosslinking capabilities, are most probably spinnable and should produce continuous fibers. Unfractionated, PKL, and $>5 \mathrm{kDa}$ molecular weight fractions, on the other hand, do not soften sufficiently for continuous spinning, and the addition of plasticizers or a chemical modification of the lignin may be required prior to thermal processing.

\section{CONCLUSIONS}

1. Ultrafiltration of industrial black liquor enables the efficient fractionation of kraft lignin in accordance with molecular weight cut-offs of membranes. Only higher MW fractions, e.g., $>5 \mathrm{kDa}$, contain a noticeable amount (3-5\%) of sugars. The lower MW fractions have significantly higher contents of sulfur than the high MW fractions.

2. The lignin fractions had different amounts of functional groups, which correlated with their MW-with decreasing molecular size, the lignin fractions tend to contain more phenolic hydroxyl groups, and fewer aliphatic hydroxyl groups. The content of carboxylic groups was not affected by fractionation.

3. The thermo-mechanical properties of lignin fractions showed a good correlation with their molecular weight. By fractionation it may be possible to tailor the $T_{g}$ of lignin$T_{g}$ 's between $70^{\circ} \mathrm{C}$ and $170^{\circ} \mathrm{C}$ were obtained. This was confirmed by analyses using both, the DSC and DMA method.

4. The $T_{g}$ s obtained from DSC and DMA followed the FoxFlory equation; the Fox-Flory parameters showed that high temperature exposure increased crosslink density in the lignin samples.

5. DMA method showed that low-molecular weight lignin fractions exhibit good flow behaviors as well as hightemperature crosslinking capability. Experimental data suggest that these fractions are suitable for e.g., melt spinning and should produce continuous fibers as a single component. Unfractionated and high molecular weight fractions (e.g., $>5 \mathrm{kDa}$ ), on the other hand, do not soften sufficiently for continuous spinning.

\section{ACKNOWLEDGMENTS}

Knut and Alice Wallenberg foundation in association with the Wallenberg Wood Science Center (WWSC). The Swedish Institute (Baltic Sea cooperation program, project 001-3053). The Gunnar
Sundblad Research Foundation. Cost Action FP1105 Wood CellNet

\section{AUTHOR CONTRIBUTIONS}

Dr. Sevastyanova O.: Planned the research, performed molecular weight (at URTV, Italy) and thermal analyses TGA, DSC (at UBC, Canada), coordinated the communication between coauthors in Sweden, Canada and Italy and wrote the manuscript. Ms. Helander M.: Helped with ultrafiltration experiment, performed chemical composition and elemental analysis, contributed to the writing of manuscript. Dr. Chowdhury S.: Performed the Dynamic rheology (DMA) analysis, wrote the part of the manuscript dealing with DMA analysis and the application of the Fox-Flory theory to the lignin fractions, contributed to the discussion related to the thermal properties of lignin. Dr. Lange H.: Helped with the molecular weight analysis, contributed to the discussions related to the 31P NMR analysis, participated in the writing of the manuscript. Dr. Wedin H.: Performed the ultrafiltration experiment and the extraction of lignin fractions. Dr. Chang L.: Performed the 31P NMR analysis. Prof. Ek M.: Encouraged to undertake of the present study, participated in the evaluation of results and discussions. Prof. Kadla J.F.: Advised on the studies of the thermal properties of lignin and lignin fractions, participated in the evaluation of results and discussions (hosted Dr. Sevastyanova at his Laboratory of Advanced Biobased Materials at UBC, Vancouver, Canada during July-August 2012. This visit was financially supported by the The Gunnar Sundblad Research Foundation). Prof. Crestini C.: Advised on the studies of the molecular weight and chemical structure of lignin and lignin fractions, participated in the evaluation of the results and discussions (hosted Dr. Sevastyanova at her laboratory at University 'Tor Vergata', Rome, Italy during the February 2013. This visit was financially supported by the Cost Action FP1105 Wood CellNet). Prof. Lindström M.E.: Supervised the research, advised on the design of the ultrafiltration experiment and the isolation of lignin fractions, participated in the evaluation of the results and discussions.

\section{REFERENCES}

1. Connor, E. TAPPI J, Bonus issue, 2008, 4.

2. Pye, E. K. In Biorefineries-Industrial Processes and Products; Kamm, B., Gruber, P. R., Kamm, M., Eds.; Wiley-VCH Verlag GmbH \& Co. KGaA: Weinheim, Germany, 2006; Vol. 2, p. 165.

3. Lin, S. Y.; Detroit, W. In Chemical Heterogeneity of Technical Lignins: Its Significance in Lignin Utilization, Proceedings of the 1st International Symposium on Wood and Pulping Chemistry, Stockholm, Sweden, June 9-12, 1981, 44-52; SPCI: Stockholm, 1981.

4. Glasser, W. G.; Kelley, S. S. In Concise Encyclopedia of Polymer Science and Engineering; Kroschwitz, Ed.; Wiley: New York, 1990; p. 544.

5. Sjöström, E. In: Wood Chemistry: Fundamentals and Applications; Academic Press: Orlando, 1981; Chapter 7, pp.124-139.

6. Loutfi, H.; Blackwell, B.; Uloth, V. Tappi J. 1991, 74, 203. 
7. Wallberg, O.; Jönsson, A.-S. Desalination 2003, 156, 145.

8. Wallberg, O.; Holmqvist, A.; Jönsson, A.-S. Desalination 2005, 180, 109.

9. Axelsson, E.; Olsson, M. R.; Berntsson, T. Nordic Pulp Paper Res. J. 2006, 21, 485.

10. Brodin, I.; Sjöholm, E.; Gellerstedt, G. Holzforschung 2009, 63, 290.

11. Gierer, J. Svensk Papperstidning 1970, 73, 571.

12. Mörck, R.; Yoshida, H.; Kringstad, K.; Hatakeyama, H. Holzforschung 1986, 40, 51.

13. Yoshida, H.; Mörck, R.; Kringstad, K. P.; Hatakeyama, H. J. Appl. Polym. Sci. 1990, 40, 1819.

14. Kubo, J. F.; Uraki, Y.; Sano, Y. Holzforschung 1996, 50, 144.

15. Li, Y.; Sarkanen, S. In Lignin: Historical, Biological and Material Perspectives; Glasser, W. G., Northey, R. A., Schultz, T. P., Eds.; ACS: Washington, DC., 2000, pp 351366.

16. Thring, R. W.; Vanderlaan, M. N.; Griffin, S. L. J. Wood Chem. Technol. 1996, 16, 139.

17. Sun, R.-C.; Tomkinson, J.; Bolton, J. Polym. Degrad. Stab. 1999, 63, 195.

18. Cui, C.; Sun, R.; Argyropoulos, D. ACS Sustain. Chem. Eng., 2014, published online January 30th, 2014 (DOI 10.1021/ sc400545d).

19. Garcia, A.; Toledano, A.; Serrano, L.; Egües, G. M.; Marin, F.; Labidi, J. Sep. Purif. Technol. 2009, 68, 193.

20. Forss, K.; Fuhrmann, A. Paperi ja Puи 1976, 58, 817.

21. Wallberg, O.; Jönsson, A. S. Chem. Eng. Res. Des. 2003, 81, 1379.

22. Keyoumu, A.; Sjödahl, R.; Henriksson, G.; Ek, M.; Gellerstedt, G.; Lindström, M. E. Ind. Crop Prod 2004, 20, 143.

23. Jönsson, A.-S.; Nordin, A.-K.; Wallberg, O. Chem. Eng. Res. Des. 2008, 86, 1271.

24. Toledano, A.; Serrano, L.; Garcia, A.; Mondragon, I.; Labidi, J. Chem. Eng. J. 2010, 157, 93.

25. Helander, M.; Theliander, H.; Lawoko, M.; Henriksson, G.; Zhang, L.; Lindström, M. E. BioResources 2013, 8, 2270.

26. Braun, J. L.; Holtman, K. M.; Kadla, J. F. Carbon 2005, 43, 385.

27. Kubo, S.; Kadla, J. F. J. Appl. Polym. Sci. 2005, 98, 1437.

28. Brodin, I.; Sjöholm, E.; Gellerstedt, G. J. Anal. Appl. Pyrol. 2010, $87,70$.

29. Jönsson, A.-S.; Wallberg, O. Desalination 2009, 237, 254.

30. Dence, C. W. In Methods in Lignin Chemistry; Lin, S. Y., Dence, C., Eds., Springer-Verlag: Heidelberg, Germany, 1992, pp 33-61.

31. Maekawa, E.; Ichizawa, T.; Koshijima, T. J. Wood Chem. Technol., 1989, 9, 549.

32. Guerra, A.; Filpponen, I.; Lucia, L. A.; Argyropolous, D. S. J. J. Agric. Food Chem. 2006, 54, 9696.

33. Granata, A.; Argyropolous, D. S. J. J. Agric. Food Chem. 1995, 43, 1538.
34. Chowdhury, S.; Fabiyi, J.; Frazier, C. E. Holzforschung 2010, 64, 747.

35. Connors, W. J.; Sarkanen, S.; McCarthy, J. L. Holzforschung $1980,34,80$

36. Sarkanen, S.; Teller, D. C.; Hall, J.; McCarthy, J. L. Macromolecules 1981, 14, 426.

37. Sarkanen, S.; Teller, D. C.; Abramowski, E.; Mccarthy, J. L. Macromolecules 1982, 15, 1098.

38. Norgren, M.; Edlund, H.; Wågberg, L. Langmuir 2002, 18, 2859.

39. Cathala, A.; Saake, B.; Faix, O.; Monties, B. J. Chromatogr. A 2003, 1020, 229

40. Baumberger, S.; Abaecherli, A.; Fasching, M.; Gellerstedt, G.; Gosselink, R.; Hortling, B.; Li, J.; Saake, B.; de Jong, E. Holzforschung 2007, 61, 459.

41. Guerra, A.; Gaspar, A. R.; Contreras, S.; Lucia, L. A.; Crestini, C.; Argyropoulos, D. S. Phytochemistry 2007, 68, 2570.

42. Asikkala, J.; Tamminen, T.; Argyropoulus, D. S. J. Agric Food Chem. 2012, 60, 8968.

43. Lawoko, M.; Henriksson, G.; Gellerstedt, G. Biomacromolecules 2005, 6, 3467.

44. Balakshin, M.; Capenema, E.; Gracz, H.; Chang, H.-M.; Jameel, H. Planta 2011, 233, 1097.

45. Zhang, L.; Gellerstedt, G. Lignin Fractionation and Quantitative Structural Analysis of the Lignin Fractions with 13C and HSQC NMR Techniques, Proceedings, Postsymposium Workshop of the 11th International Symposium on Wood and Pulping Chemistry, Grenoble, France, 2001, 3, p. 595.

46. Hodge, I. M. J. Non-Crystalline Solids 1994, 169, 211.

47. Rials, T. G.; Glasser, W. G. J. Wood Chem. Technol. 1984, 4, 331.

48. Guido, N.; Mija, A.; Vincent, L.; Sbirrazzuoli, N. Phys. Chem. Chem. Phys. 2009, 11, 1227.

49. Fox, T. G.; Flory, P. J. J. Am. Chem. Soc. 1950, 70, 2384.

50. Montserrat, S.; Colomer, P. Polym. Bull. 1984, 12, 173.

51. Cui, C.; Sadeghifar, H.; Sen, S.; Argyropoulos, D. S. BioResources 2013, 8, 864 .

52. Dallmeyer, I.; Chowdhury, S.; Kadla, J. F. Biomacromolecules, 2013, 1, 2354.

53. Uraki, Y.; Sugiyama, Y.; Koda, K.; Kubo, S.; Kishimoto, T.; Kadla, J. F. Biomacromolecules, 2012, 13, 867.

54. Ferry, J. D. Viscoelastic Properties of Polymers, 3rd ed.; Wiley: New York, 1980.

55. Fox, J. T. G.; Flory, P. J. J. Appl. Phys. 1950, 21, 581.

56. Kelley, S. S.; Ward, T. C.; Rials, T. G.; Glasser, W. G. J. Appl. Polym. Sci. 1989, 37, 2961.

57. Chowdhury, S.; Gao, G.; Kadla, J. F. Investigating the Viscoelasticity of Lignin-Polyacrylonitrile Blends using Dynamic Rheology, Proceedings, 243rd ACS meeting, CELL 119, March 25-29, 2012, San Diego, California, USA. 